Article

\title{
In Situ Observation for Deformation-Induced Martensite Transformation during Tensile Deformation of SUS 304 Stainless Steel by Using Neutron Diffraction PART II: Transformation and Texture Formation Mechanisms
}

\author{
Yusuke Onuki ${ }^{1, *(D)}$ and Shigeo Sato ${ }^{2}$ (DD \\ 1 Frontier Research Center for Applied Atomic Sciences, Ibaraki University, 162-1 Shirakata, Tokai, \\ Ibaraki 319-1106, Japan \\ 2 Graduate School of Science and Engineering, Ibaraki University 4-12-1 Nakanarusawa, Hitachi, \\ Ibaraki 316-8511, Japan; shigeo.sato.ar@vc.ibaraki.ac.jp \\ * Correspondence: yusuke.onuki.0@vc.ibaraki.ac.jp; Tel.: +81-29-352-3234
}

check for updates

Citation: Onuki, Y.; Sato, S. In Situ Observation for Deformation-Induced Martensite Transformation during Tensile Deformation of SUS 304 Stainless Steel by Using Neutron Diffraction PART II: Transformation and Texture Formation Mechanisms. Quantum Beam Sci. 2021, 5, 6. https://doi.org/10.3390/qubs5010006

Received: 27 December 2020

Accepted: 26 January 2021

Published: 2 February 2021

Publisher's Note: MDPI stays neutral with regard to jurisdictional claims in published maps and institutional affiliations.

Copyright: (c) 2021 by the authors. Licensee MDPI, Basel, Switzerland. This article is an open access article distributed under the terms and conditions of the Creative Commons Attribution (CC BY) license (https:// creativecommons.org/licenses/by/ $4.0 /)$.

\begin{abstract}
Herein, the texture developments of $\gamma$ austenite, $\varepsilon$ martensite, and $\alpha^{\prime}$ martensite during the tensile deformation of SUS 304 stainless steel were observed by using the in situ neutron diffraction technique. Combined with the microstructure and local orientations measured by electron backscattered diffraction (EBSD), the mechanisms involved in the deformation-induced martensite transformation (DIMT) in the SUS 304 stainless steel were examined based on the neutron diffraction results. The results revealed that the $\varepsilon$ martensite inherited the texture of the $\gamma$ austenite, that is, their main components could be connected by Shoji-Nishiyama orientation relationship. The variant selection was qualitatively evaluated based on the Schmid factors of the $\{111\}\langle\overline{2} 11\rangle$ slip systems. The results revealed that the $\varepsilon \rightarrow \alpha^{\prime}$ transformation occurred easily in the steel sample. Consequently, the volume fraction of the $\alpha^{\prime}$ martensite phase observed by EBSD was higher than that observed by neutron diffraction. In addition, at a true strain of 0.42 , a packet structure consisting of two $\alpha^{\prime}$ martensite variants was observed in the steel sample. However, the original orientation of the variants did not correspond to the main components in the $\gamma$ or $\varepsilon$ phases. This suggests that the two $\alpha^{\prime}$ martensite variants were transformed directly from the lost component of the $\gamma$ matrix. These results indicate that the $\gamma \rightarrow \varepsilon \rightarrow \alpha^{\prime}$ DIMT was first activated in the steel sample, after which the $\gamma \rightarrow \alpha^{\prime}$ DIMT was activated at the later stage of deformation.
\end{abstract}

Keywords: TRIP effect; neutron diffraction; 304 stainless steel; texture

\section{Introduction}

The transformation-induced plasticity (TRIP) effect in austenitic steels has been reported since the 1950s [1]; however, its mechanism is yet to be fully understood. The complexity of the TRIP effect can be attributed to the formation of $\varepsilon$ martensite as an intermediate phase during the $\gamma \rightarrow \alpha^{\prime}$ deformation-induced martensite transformation (DIMT) in steel. Although the formation of $\varepsilon$ martensite by DIMT is well-known, it has rarely been investigated from an engineering aspect [2]. Several researchers have extensively investigated the relationship between the $\alpha^{\prime}$ martensite fraction and the mechanical properties of steel, particularly, the strain-hardening rate [2,3]. However, to achieve the desired mechanical properties in steel by controlling its chemical composition and/or microstructure, it is necessary to understand the effects of the $\gamma \rightarrow \varepsilon \rightarrow \alpha^{\prime}$ and $\gamma \rightarrow \alpha^{\prime}$ DIMT mechanisms on the deformation of steel. Masumura et al. investigated the DIMT behaviors of $18 \mathrm{Cr}-8 \mathrm{Ni}$ steels containing 0.1 mass $\% \mathrm{C}$ or $\mathrm{N}$ by a rolling process [4]. They found that the quenched $0.1 \mathrm{C}$ steel contained more thermal $\alpha^{\prime}$ martensite than the quenched $0.1 \mathrm{~N}$ steel. Contrarily, more $\alpha^{\prime}$ martensite was formed in the deformed $0.1 \mathrm{~N}$ steel than in the deformed $0.1 \mathrm{C}$ steel. However, more deformation-induced $\varepsilon$ martensites were observed in $0.1 \mathrm{C}$ 
steel than in $0.1 \mathrm{~N}$ steel. Tiamyu et al. observed $\varepsilon$ martensite in coarse-grained $(37 \mu \mathrm{m})$ compression-deformed AISI 321 steel, but not in the fine-grained $(0.24 \mu \mathrm{m})$ sample [5]. However, more $\alpha^{\prime}$ martensites were formed by DIMT in the fine-grained sample than in the coarse-grained sample. These observations indicate that the $\gamma \rightarrow \varepsilon$ DIMT mechanism is important for explaining the development of $\alpha^{\prime}$ martensite and the mechanical properties of steel.

In this paper, we discuss the results from our previous experiment on 304 stainless steel (Part I) [6] from a different aspect. In Part I, we discuss the relationship between the mechanical behavior of 304 stainless steel and the volume fraction of the formed martensite, as well as the dislocation structure in the austenite phase.

In this study, we focused on the texture developments of the $\gamma, \varepsilon$, and $\alpha^{\prime}$ phases. The results are discussed by combining the overall average textures measured by neutron diffraction and the local misorientations measured by electron backscattered diffraction (EBSD). The results revealed that the texture of the $\varepsilon$ phase can be understood based on the inheritance of the texture components of the $\gamma$ matrix and the activation of $\{111\}\langle\overline{2} 11\rangle$ the slip system. In addition, examinations of the $\alpha^{\prime}$ orientations revealed that the DIMT did not necessarily go through the $\gamma \rightarrow \varepsilon \rightarrow \alpha^{\prime}$ route, but the $\gamma \rightarrow \alpha^{\prime}$ route. Furthermore, the original $\gamma$ matrix orientation corresponding to the observed $\alpha^{\prime}$ orientations differed from the main texture component of the $\gamma$ matrix. These observations indicate that the $\gamma \rightarrow \varepsilon \rightarrow \alpha^{\prime}$ DIMT was initially activated, but $\gamma \rightarrow \alpha^{\prime}$ DIMT was activated in the latter stage of deformation.

\section{Materials and Methods}

\subsection{Sample and Experiment}

The data used in this study were the same data reported in our previous study, (PART I) [6] and were obtained by in situ neutron diffraction experiments during tensile deformation using iMATERIA at the Japan Proton Accelerator Research Complex, Materials and Life Science Experimental Facility (J-PARC MLF, Ibaraki, Japan). Although detailed explanations of the samples, experiments, and analysis are described in PART I, some essential parts are described in Section 2.1.

Commercial SUS 304 stainless steel was used as the sample. The tensile test was conducted at a constant crosshead speed of $0.3 \mathrm{~mm} / \mathrm{min}$ at room temperature $(300 \mathrm{~K})$. The diffraction data were acquired every $1800 \mathrm{~s}$ and were used for the analysis. The increment in the strain every $1800 \mathrm{~s}$ corresponded to approximately $0.02-0.025$.

The diffraction patterns of the steel sample were recorded at 132 observation points, using iMATERIA. The 132 diffraction patterns were simultaneously fitted by considering the texture, using the Rietveld texture analysis (RTA) method. Consequently, some properties of the materials were obtained. In Part I, the mechanical response of the steel sample was discussed based on the development of the phase fractions and line profile parameters. Herein, the mechanical properties of the steel sample were discussed based on the textures of the formed phases, which were simultaneously determined with the aforementioned parameters.

The RTA was conducted using the MAUD software (Trento, Italy) (ver. 2.9.3). [7] The entropy-modified Williams-Imhof-Matthies-Vinel (E-WIMV) was applied as the orientation distribution function (ODF) calculation method, with a $5^{\circ}$ resolution for austenite and $\alpha^{\prime}$ martensite, and $10^{\circ}$ resolution for $\varepsilon$ martensite. At this stage, we did not assume any sample symmetry. For further analysis, the ODFs were calculated from the pole figures exported from the MAUD software, using the MTEX toolbox (ver. 5.3.1) on MATLAB (2020a) [8]. Hereafter, the Euler angles are expressed based on the Bunge's definition [9]. For the hexagonal close-packed $\varepsilon$ martensite, the crystal basis was set such that $x$ was parallel to [2110], that is, the $a$ axis of the unit cell. The ODF plots in the Euler space were calculated with an orthorhombic sample symmetry.

EBSD measurements were conducted by using a scanning electron microscope (Hitachi SU5000, Tokyo, Japan) equipped with an EDAX OIM system. The microstructures of the steel sample were observed in the mid layer parallel to the sheet plane. 


\subsection{Numerical Analysis of the Transformation Orientation Relationships}

To determine the texture components of the three phases, simple transformation texture calculations were conducted. For the $\gamma \rightarrow \varepsilon$ DIMT, the two phases exhibit the ShojiNishiyama (S-N) orientation relationship, that is, $(111)_{\gamma} \|(0001)_{\varepsilon}$ and $[\overline{101}]_{\gamma} \|[2 \overline{110}]_{\varepsilon}$. This transformation can be assumed to be a simple shear on the $\{111\}\langle\overline{2} 11\rangle$ slip system. Therefore, the orientation of the $\varepsilon$ phase was obtained by rotating the $z$ and $x$ of the crystal basis corresponding to the $[111]_{\gamma}$ and $[101]_{\gamma}$. This rotation can be expressed by using Euler angles as follows: $\left(45^{\circ}+90^{\circ} i, 54.74^{\circ}, 60^{\circ} j\right)$, where $i=0,1, \ldots, 3$ and $j=0,1, \ldots, 5$. Although the variations of $j$ fall in the equivalent orientation, each corresponds to the activation of different $\{111\}\langle\overline{2} 11\rangle$ slips. The rotation matrix $\left(R_{1}\right)$ was calculated from the set of the Euler angles. The crystal orientation of the $\gamma$ phase $\left(g_{\gamma}\right)$ was also represented by using the rotation matrix $\left(G_{\gamma}\left(g_{\gamma}\right)\right)$, which is defined by the Euler angles [9]. Hence, the orientation of the $\varepsilon$ phase $\left(G_{\varepsilon}\right)$ can be calculated as follows:

$$
G_{\varepsilon}=R_{1} G_{\gamma}
$$

Consequently, the inverse manipulation can be obtained by applying the inverse rotation matrix:

$$
G_{\gamma}=R_{1}^{-1} G_{\varepsilon}=R_{1}^{\mathrm{T}} G_{\varepsilon}
$$

This can be used to observe the origin of the orientation of the product.

The transformation texture was calculated by applying Equation (1) to all the orientations of the $\gamma$ austenite phase. In this study, the $\gamma \rightarrow \varepsilon$ DIMT was estimated by using the transformation texture calculations. First, the ODF of the $\gamma$ matrix was discretized into 5000 orientations. Subsequently, from each matrix orientation, 24 variants were calculated for the $\varepsilon$ phase. These variants corresponded to $\{111\}\langle\overline{2} 11\rangle$ slip systems, considering the directional signs, that is, $[\overline{211}]$ and [211] were separately considered. Consequently, the $\varepsilon$ phase formed by the six systems on a certain $\{111\}$ plane had the same crystal orientation. However, they were treated separately for the subsequent Schmid factor considerations. By integrating 120,000 (i.e., $24 \times 5000$ ) orientations without any weight, a transformation texture with no variant selection rule was obtained.

To observe the effect of the Schmid factors of the $\{111\}\langle\overline{2} 11\rangle$ systems on the variant selection, the Schmid factor was applied as the weight of the ODF integration process. The Schmid factors can be negative for certain slip systems. This indicates that the activation of the system produced a compressive strain in the selected tensile direction. Hence, the system was inactive during the tensile deformation, and the corresponding weight was set to zero. The aforementioned discretization and reintegration of the ODF were conducted by using the MTEX toolbox.

The consideration of the $\gamma \rightarrow \alpha^{\prime}$ or $\varepsilon \rightarrow \alpha^{\prime}$ DIMT was more complicated than that of the $\gamma \rightarrow \varepsilon$ DIMT, owing to the large lattice distortion and deviation from the exact KurdjumovSachs $(\mathrm{K}-\mathrm{S})$ orientation relationship, $(111)_{\gamma}\left\|(011)_{\alpha^{\prime}},[\overline{101}]_{\gamma}\right\|[\overline{111}]_{\alpha^{\prime}}$. The total lattice distortion matrix $\left(P_{1}\right)$ can be expressed as follows [1]:

$$
P_{1}=R_{2} B P
$$

where $R_{2}$ is the rigid body rotation matrix, $B$ is the Bain distortion, and $P$ is the complementary shear. $B$ was calculated by using the lattice parameters of the $\gamma$ and $\alpha^{\prime}$ phases. In this study, we used $a_{0}=0.35945 \mathrm{~nm}$ for $\gamma$ and $\mathrm{a}=\mathrm{c}=0.28743 \mathrm{~nm}$ for $\alpha^{\prime}$ based on the results of the neutron diffraction analysis. Because the lattice parameter of martensite was determined under stress, it may contain certain errors. However, the first three digits should be reliable. Therefore, the $R_{2}, P$, and $P_{1}$ were determined such that the total distortion exhibited an invariant plane, and the direction followed the Bowles-Mackenzie theory [10], as explained in the book by Nishiyama [1]. As $B$ and $P$ have no effect on the crystal orientation, the orientation of the $\alpha^{\prime}$ martensite can be calculated with $R_{2}$ and the Bain coordinate transformation. 


\section{Results}

\subsection{Texture Development Observed by In Situ Neutron Diffraction}

Figure 1 shows pole figures of the $\gamma$ austenite at various strains. The initial texture of the $\gamma$ austenite was a weak rolling texture with an orthorhombic symmetry. With an increase in the strain, alignments of the $\{111\}$ and $\{001\}$ poles along the tensile direction were gradually strengthened. In addition, the poles' distribution gradually formed a fiber symmetry around the tensile axis; however, the $\gamma$ austenite did not achieve a complete fiber texture even at a true strain of 0.42 .

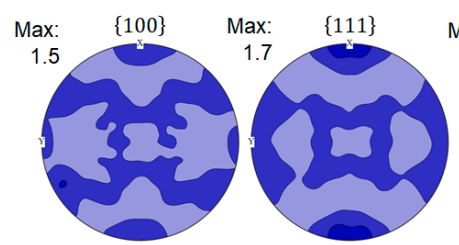

$$
\varepsilon_{t}=0
$$

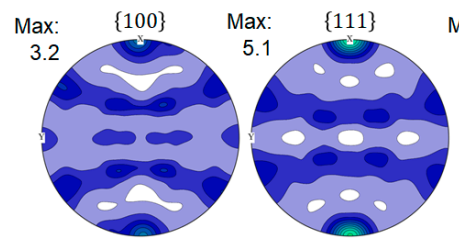

$\varepsilon_{t}=0.25$

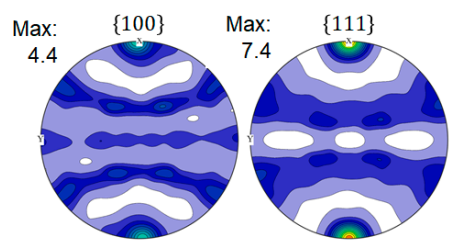

$\varepsilon_{t}=0.42$

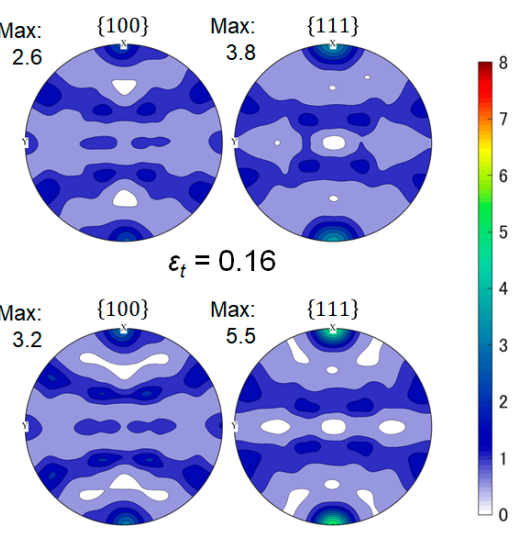

$\varepsilon_{t}=0.30$

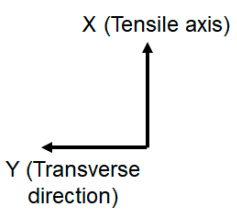

Figure 1. Analyzed $\{001\}$ and $\{111\}$ pole figures of the $\gamma$ phase at various true strains $\left(\varepsilon_{t}\right)$. The contour step was 0.5 .

Pole figures of the $\varepsilon$ and $\alpha^{\prime}$ martensite phases are shown in Figures 2 and 3, respectively. Generally, the texture analysis of phases with a low volume fraction $(<3 \%)$ tends to be unreliable [11]. Therefore, in this paper, only the pole figures of the $\varepsilon$ and $\alpha^{\prime}$ martensite at strains above 0.25 are shown. The textures of the martensite phases were weaker than those of the austenite phase. However, the textures were mostly unchanged with increasing strain. In addition, the martensite phases maintained their orthorhombic symmetries regardless of the strain.

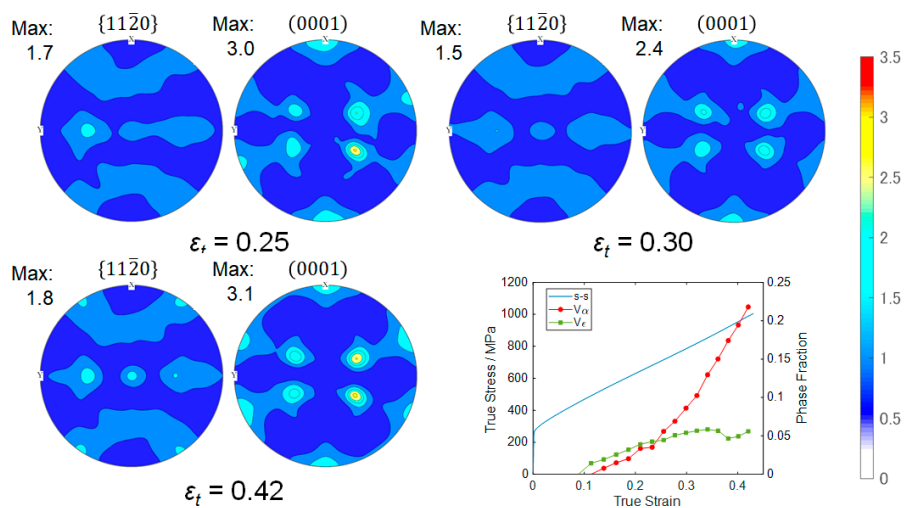

Figure 2. Analyzed $\{11 \overline{2} 0\}$ and $\{0001\}$ pole figures of the $\varepsilon$ martensite at various true strains $\left(\varepsilon_{t}\right)$. The contour step was 0.5 . The increase in the volume fractions of the $\alpha^{\prime}(\mathrm{V} \alpha)$ and $\varepsilon(\mathrm{V} \varepsilon)$ martensite phases with increasing strain is also shown. 



$\varepsilon_{t}=0.30$
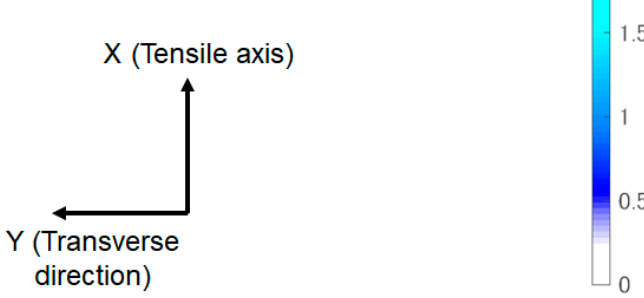

Figure 3. Analyzed $\{100\}$ and $\{110\}$ pole figures of the $\alpha^{\prime}$ martensite at various true strains $\left(\varepsilon_{t}\right)$. The contour step was 0.5 .

The texture components for the matrix and martensites were visualized by plotting the ODFs in the Euler spaces, as shown in Figures 4 and 5, respectively. Owing to the orthorhombic symmetry observed in the pole figures, the range of $\varphi_{1}$ was limited to $0^{\circ} \leq \varphi_{1}<90^{\circ}$. The main components of the textures are listed in Table 1 . As previously mentioned, the austenite phase formed strong alignments of $<111>$ and $<100>$ along the tensile axis. Among the $\{h k l\}<111>$ orientations, the rotated brass (RB) component had the highest density. In addition, Goss $(\mathrm{G})$ was the primary component of the $\{h k l\}<100>$ orientations; however, a secondary peak was observed at $\{015\}<100>$. Hereafter, the latter component is referred to as the near cube (NC) orientation. Although the NC orientations were weak, they were observed even in the initial texture (Figure $4 \mathrm{a}$ ).



Figure 4. $\varphi_{2}$ sections of the orientation distribution function (ODF) of $\gamma$ austenite at (a) $E=0$ and (b) $E=0.42$. The increment of $\varphi_{2}$ was $5^{\circ}$. 


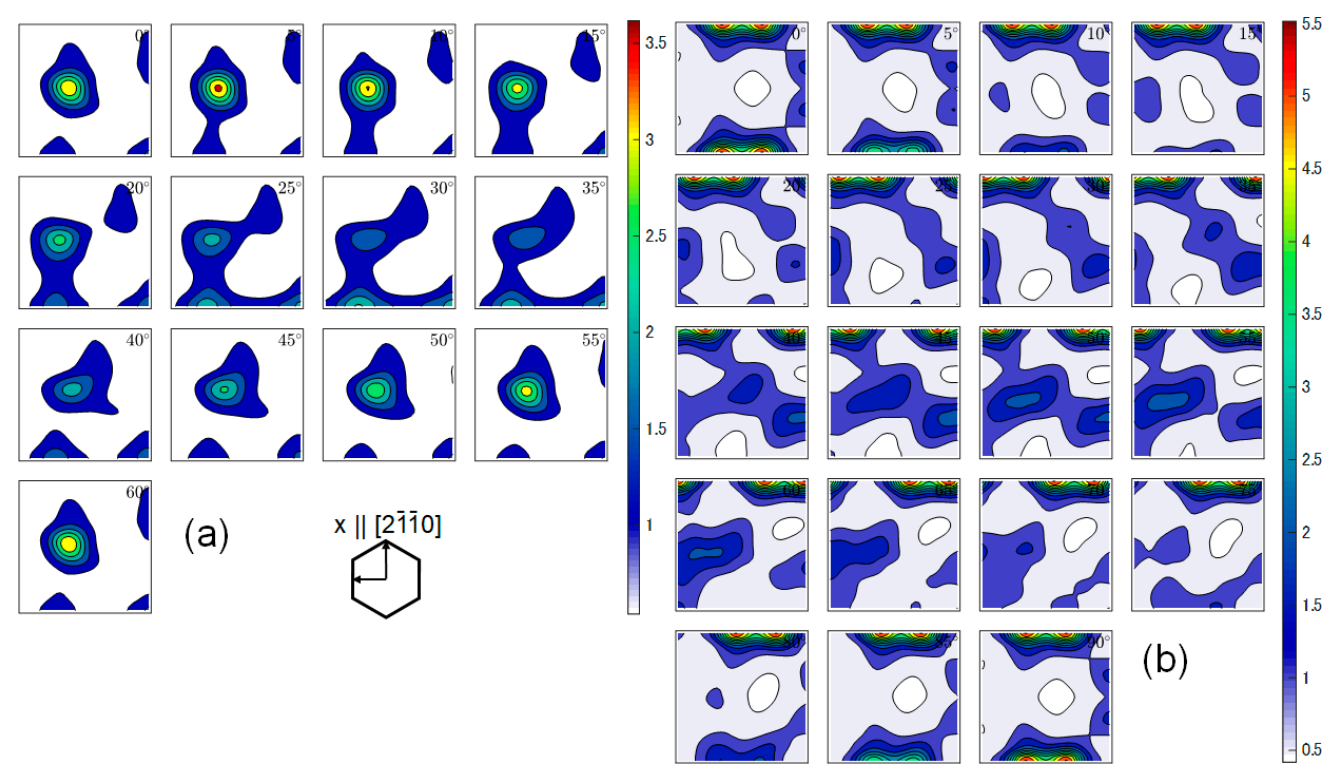

Figure 5. $\varphi_{2}$ sections of the ODF of (a) $\varepsilon$ martensite and (b) $\alpha^{\prime}$ martensite at $\varepsilon_{t}=0.42$. The increment of $\varphi_{2}$ was $5^{\circ}$.

Table 1. Texture components observed at $\varepsilon_{t}=0.42$.

\begin{tabular}{cccc}
\hline Phase & Orientation Name & Euler Angles & $\begin{array}{c}\text { Approximate } \\
\text { (hk1)[uvw] }\end{array}$ \\
\hline$\gamma$ austenite & Rotated Brass (RB) & $\left(55^{\circ}, 45^{\circ}, 0^{\circ}\right)$ & $(011)[1 \overline{1} 1]$ \\
& Goss (G) & $\left(0^{\circ}, 45^{\circ}, 0^{\circ}\right)$ & $(011)[100]$ \\
$\varepsilon$ martensite & Near cube (NC) & $\left(0^{\circ}, 12.5^{\circ}, 0^{\circ}\right)$ & $(015)[100]$ \\
& Main (M) & $\left(32.5^{\circ}, 42.5^{\circ}, 5^{\circ}\right)$ & $(01 \overline{1} 2)[4 \overline{4} 03]$ \\
$\alpha^{\prime}$ martensite & Sub 1 (S1) & $\left(15^{\circ}, 90^{\circ}, 30^{\circ}\right)$ & $(11 \overline{2} 0)[2 \overline{2} 01]$ \\
& Sub 2 (S2) & $\left(90^{\circ}, 90,30^{\circ}\right)$ & $(11 \overline{2} 0)[0001]$ \\
& $30^{\circ}$-rotated cube (30RC) & $\left(30^{\circ}, 0^{\circ}, 0^{\circ}\right)$ & $(001)[5 \overline{3} 0]$ \\
& Quench 1 (Q1) & $\left(90^{\circ}, 62.5,45^{\circ}\right)$ & $(332)[\overline{11} 3]$ \\
& Quench 2 (Q2) & $\left(40^{\circ}, 47.5,45^{\circ}\right)$ & $(223)[1 \overline{4} 2]$ \\
\hline
\end{tabular}

Owing to the stability of the martensite textures, the textures of the martensite observed after deformation, when the highest volume fractions of the martensite phases were observed, are discussed. The observed texture of the $\varepsilon$ martensite consisted of one dominant and two minor components. The components are hereafter referred to as Main (M), Sub1 (S1), and Sub2 (S2), respectively.

The textures of the $\alpha^{\prime}$ martensite exhibited dominant peaks at $\left(30^{\circ}-\varphi_{2}, 0^{\circ}, \varphi_{2}\right)$ and $\left(60^{\circ}-\varphi_{2}, 0^{\circ}, \varphi_{2}\right)$, which were geometrically equivalent orientations, $\{001\}\langle 5 \overline{3} 0\rangle$. Hereafter, the orientations are referred to as the $30^{\circ}$-rotated cube $(30 \mathrm{RC})$ component. The other component, Quench 1 (Q1) (Table 1), is often observed in acicular ferrite and martensite in low-alloyed steels transformed upon cooling [12]. However, Q2 has not been frequently reported in literature, but is often observed in transformation textures.

\subsection{Microtextures Observed by EBSD}

Figure 6 shows the microstructure and orientations of the deformed sample up to a true strain of 0.11 . According to the neutron diffraction results, austenite and $\varepsilon$ martensite were formed in this sample; however, $\alpha^{\prime}$ martensite should be almost zero (see Figure 2). In contrast, the EBSD observations revealed that the volume fraction of the $\alpha^{\prime}$ martensite in the steel sample was larger than that of the $\varepsilon$ martensite. This could be attributed to the formation of the $\alpha^{\prime}$ martensite phase during the surface preparation of the steel, such as the cutting and polishing processes [13]. Alternatively, this could be attributed to the change 
in the environment around the $\varepsilon$ martensite by the surface of the steel, thus resulting in the $\varepsilon \rightarrow \alpha^{\prime}$ transformation.

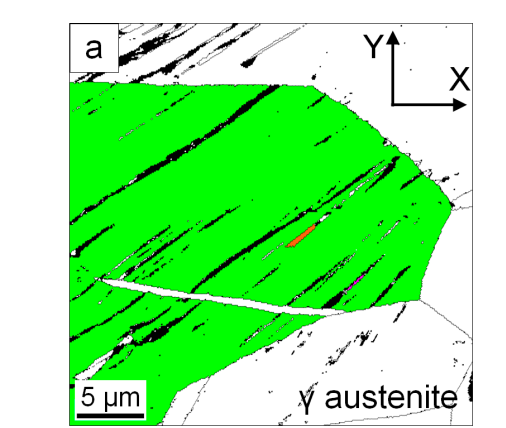

(d)

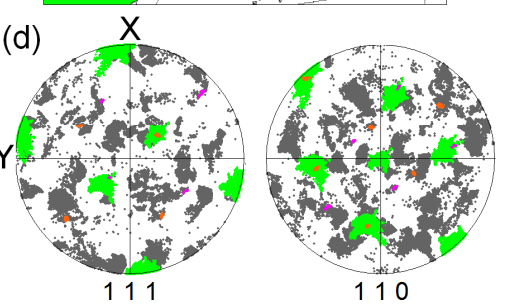

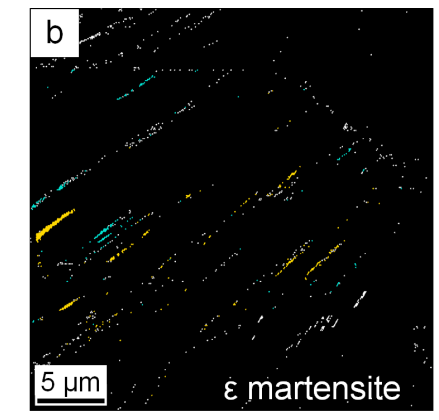

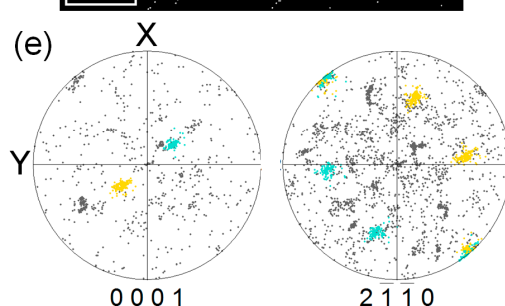


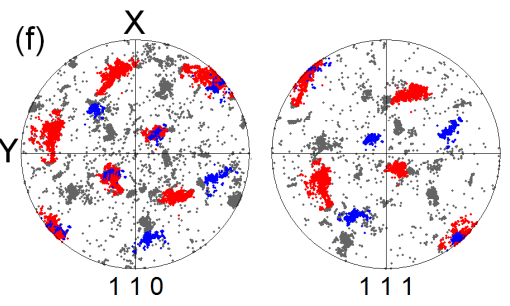

Figure 6. (a-c) Phase partition maps of the electron backscattered diffraction (EBSD) measurement results of the deformed sample up to a true strain of 0.11 . The white and colored points correspond to the selected phase. (d-f) Discrete pole figures of the corresponding phase maps. The same color highlighting is applied as in the maps; $(\mathbf{a}, \mathbf{d}) \gamma$ austenite, $(\mathbf{b}, \mathbf{e}) \varepsilon$ martensite, and $(\mathbf{c}, \mathbf{f}) \alpha^{\prime}$ martensite.

Hence, the $\alpha^{\prime}$ martensite was considered to be formed after the tensile deformation. However, its existence suggests that the $\varepsilon \rightarrow \alpha^{\prime}$ transformation occurred easily in this steel. In addition, the Burgers orientation relationship [14], $(0001)_{\varepsilon}\left\|(011)_{\alpha^{\prime}}[2 \overline{11} 0]_{\varepsilon}\right\|[\overline{111}]_{\alpha^{\prime}}$ was confirmed between the $\varepsilon$ and $\alpha^{\prime}$ phases. In addition to the S-N orientation relationship between the $\gamma$ and $\varepsilon$ phases, a K-S orientation relationship was observed between the $\gamma$ and $\alpha^{\prime}$ phases.

The highlighted pole figures revealed that the $\varepsilon$ phase exhibited two different orientations (Figure 6e). Considering the sample symmetry and orientation of the matrix grain ((011) $\gamma$ perpendicular to Z), the results revealed that these orientations were geometrically equivalent orientations. The Euler angles of these $\varepsilon$ martensite orientations were approximately $\left(40^{\circ}, 30^{\circ}, 0^{\circ}\right) \varepsilon$ and $\left(220^{\circ}, 30^{\circ}, 0^{\circ}\right) \varepsilon$. Technically, based on the S-N relationship, the $\left(40^{\circ}, 35^{\circ}, 0^{\circ}\right) \varepsilon$ component was expected to originate from approximately the center of the observed orientations of the $\gamma$ phase, $\left(310^{\circ}, 45^{\circ}, 0^{\circ}\right) \gamma$.

The orientations shown in Figure $6 \mathrm{f}$ are close to the Q2 components; however, it is unclear if these $\alpha^{\prime}$ martensite phases were transformed during the deformation test. In addition, in this microstructure, the main component of $\alpha^{\prime}$ martensite (30RC) was not observed inside the RB-oriented matrix grain.

Figure 7 shows the microstructure of the steel sample at a strain of 0.42 . The $\varepsilon$ martensite was almost not observed at a strain of 0.42 . This indicates that the unstable $\varepsilon$ martensite phase disappeared during the surface preparation of the sample. This could be one of the reasons why the existence of $\varepsilon$ martensite in 304 stainless steel is often ignored or overlooked in the literature.

As shown in Figure 7a, a fishbone-shaped retained austenite structure with a $<111>$ | I X (blue) alignment can be observed. The formation of the fishbone structure could be attributed to the formation of the martensite band shown in Figure 6. In addition, vast $<100>$ I I X (red) regions were confirmed, from which the original grain shape was easily observed. This suggests the orientation preference of DIMT. However, the findings of this study are not consistent with those of Yamasita et al., on a low-alloyed TRIP steel [15], in 
which they reported that $<111>$-oriented grains survived more than $<100>$ - and $<110>-$ oriented grains.

As shown in Figure $7 \mathrm{~b}, \mathrm{c}$, the retained fishbone-shaped austenite is mainly oriented to the RB component, (011) [11 11$]$. In addition, the surrounding martensite had a complex structure consisting of two different orientations: Q2 (blue) and near 30RC (red) components.

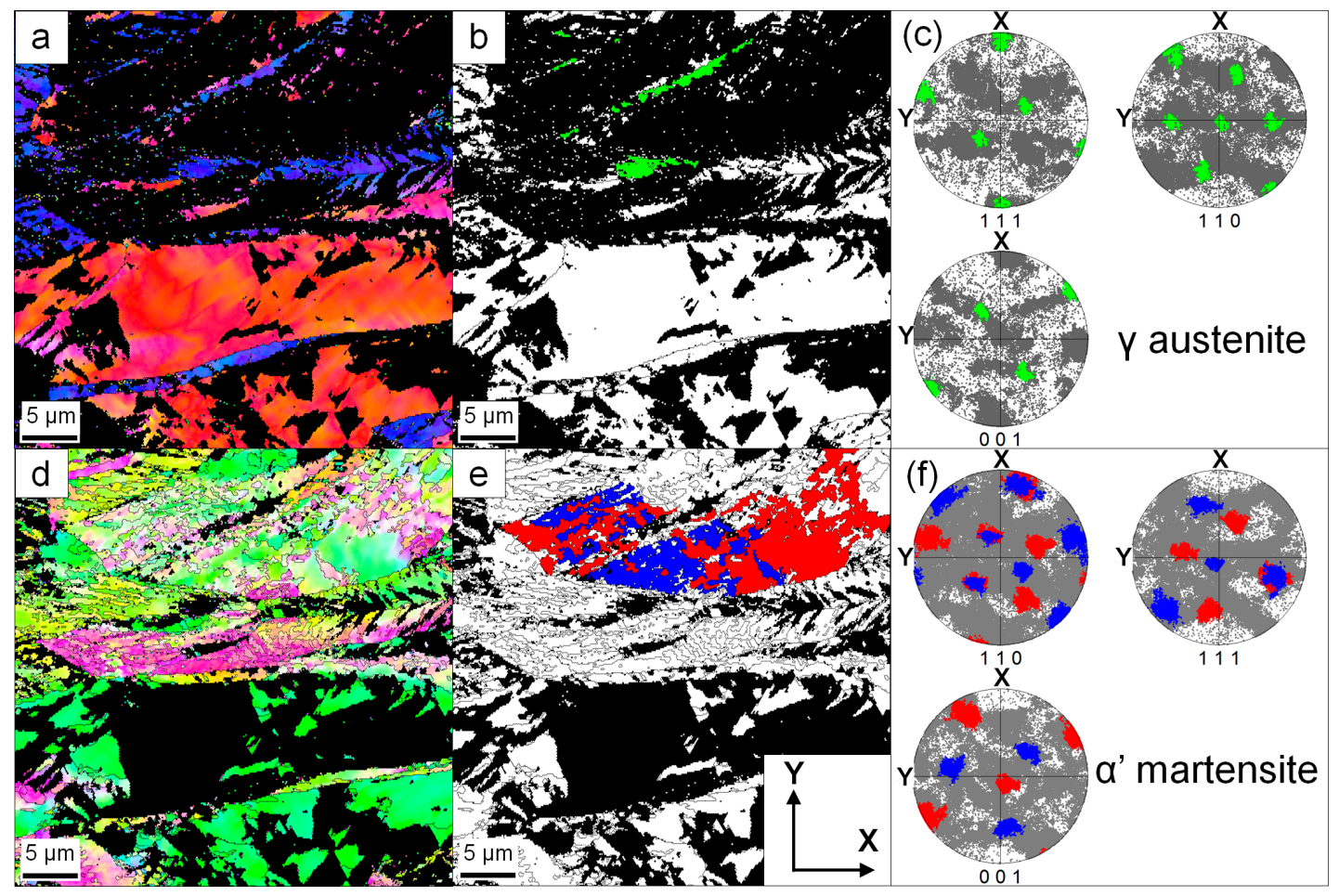

Figure 7. Phase partition maps and corresponding discrete pole figures of the deformed sample obtained by EBSD measurement up to a true strain of 0.42. (a,d) Inverted pole figures (IPF) (X) maps, (b,e) colors highlighted in the blank maps, and (d,f) highlighted pole figures of the $(\mathbf{a}-\mathbf{c}) \gamma$ austenite and $(\mathbf{d}-\mathbf{f}) \alpha^{\prime}$ martensite measured at a true strain of 0.42. Note that the tensile axis, $X$, is horizontal in the maps, but vertical in the pole figures.

\section{Discussion}

\section{1. $\gamma \rightarrow \varepsilon$ Transformation}

The original matrix orientation can be determined from a $\varepsilon$ orientation using Equation (2) as shown in Figure 8. Figure 8a shows the M component of the $\varepsilon$ martensite on (0001) pole figure. Two possible reverse variants were observed for one orientation of $\varepsilon$ martensite. One of them, Figure $8 b$, is close to the RB orientation. The deviation from the exact RB was $7.9^{\circ}$, which is close, but too large, to be regarded as the experimental error.

This deviation could be attributed to the crystal rotation of the matrix grains. Particularly, the $\varepsilon$ martensite shown in Figure 6 does not correspond to the center of the orientation distribution of the matrix grain. In addition, the $\varepsilon$ martensite may rotate, owing to plastic deformation. As certain orientation spreads are confirmed in the martensite phases in Figure 6, the $\varepsilon$ martensite, or the region about to transform into $\varepsilon$ martensite, might experience slip deformation to some extent.

Alternatively, the deviation can be explained based on the crystal symmetry. In the exact $\mathrm{RB}$ orientation (or the orientation deviated owing to the rotation around the ND), there were two geometrically equivalent $\{111\}$ poles. These two variants can be equivalently activated to transform into $\varepsilon$ martensite if the mechanical driving force of DIMT can be explained by the Schmid factor (Figure 6e). Consequently, these non-parallel $\varepsilon$ plates intercepted each other and prevented further growth. In contrast, the geometrical equivalence of $\{111\}$ disappeared in the deviated orientation (Figure 8b). Hence, a certain (1) $\overline{11})[12 \overline{1}]$ 
system had the highest Schmid factor among the equivalent systems. Consequently, this resulted in the preferential transformation of the variant with the $(1 \overline{11})_{\gamma} \|(0001)_{\varepsilon}$ relationship, with few possibilities of interception by other variants.

(a) $\left(32.5^{\circ}, 42.5^{\circ}, 5^{\circ}\right) \varepsilon$

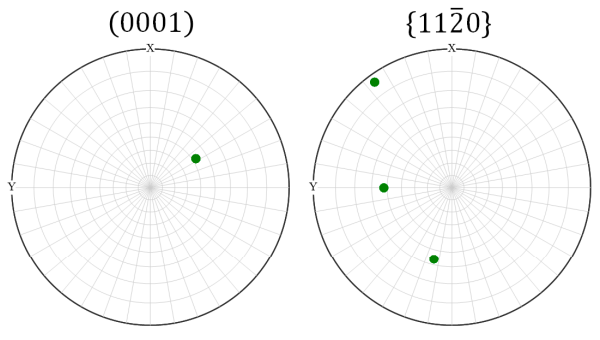

(b) $\left(118.5^{\circ}, 42^{\circ}, 10.5^{\circ}\right) \gamma$
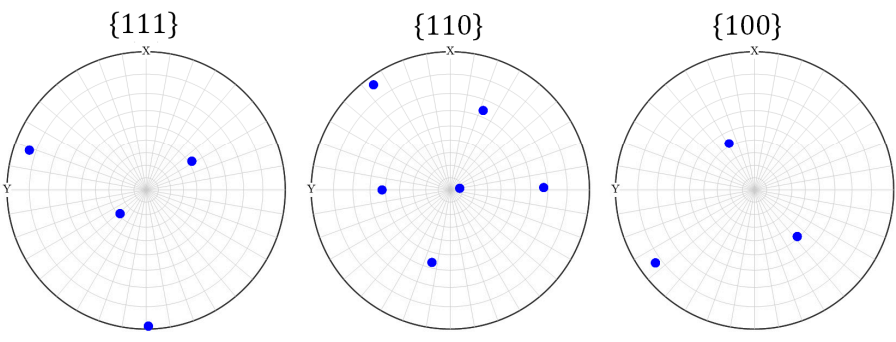

(c) $\left(231^{\circ}, 18^{\circ}, 29.5^{\circ}\right) \gamma$

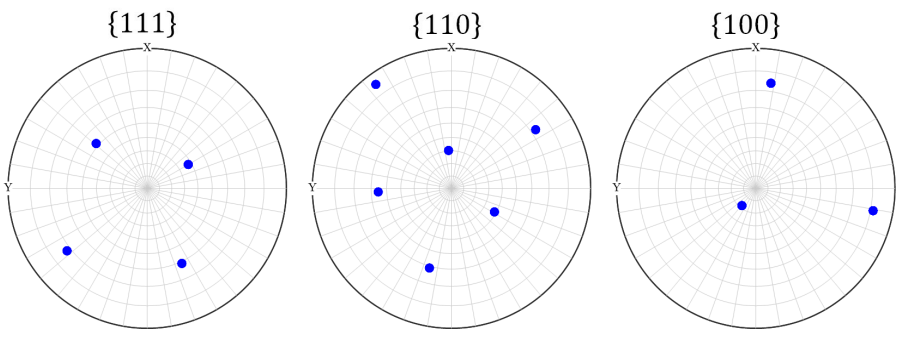

Figure 8. Pole plots of the (a) M texture component of the $\varepsilon$ phase and $(\mathbf{b}, \mathbf{c})$ the candidate orientations of the $\gamma$ phase, which can transform into the M-oriented $\varepsilon$ phase.

Although the deviation could be attributed to the aforementioned reasons, the results indicate that the main texture component of the matrix (RBs) transformed into the main component of the $\varepsilon$ martensite phase (M). In addition, the S1 and S2 components of the $\varepsilon$ martensite phase closely corresponded to the RBs component. If the texture of the $\varepsilon$ phase only reflects the texture of the $\gamma$ matrix, it can be calculated by using Equation (1), without applying variant selection rules. Figure 9 a shows the estimated ODF of the $\varepsilon$ phase from the ODF of the $\gamma$ matrix shown in Figure $4 \mathrm{~b}$. Here, the positions of the orientation concentrations were consistent with the measured positions in Figure 5a. However, the dominant component was S2, where (0001) $\varepsilon$ was perpendicular to the tensile axis. Although RBs have one of the $\{111\} \gamma$ planes, which are perpendicular to the tensile axis, the Schmid factor of the $\{111\}\langle\overline{2} 11\rangle$ systems on this plane was zero. Previous studies have reported that the Schmid factor of $\{111\}\langle\overline{2} 11\rangle$ system is a simple and valid factor for evaluating the effect of mechanical force on the activation of $\gamma \rightarrow \varepsilon$ DIMT $[16,17]$. Therefore, an ODF estimation that uses the Schmid factor as the weight was conducted. The ODF result is shown in Figure 9b. The S2 component was suppressed, and the dominant component was the near M component. This result is more consistent with the measured ODF compared with the estimated ODF in Figure 9a; however, the peak positions were not perfectly consistent. This result indicates that a more accurate estimate can be obtained by considering other factors, such as the effects of the symmetry and transformation timing on the microstructure formation. 


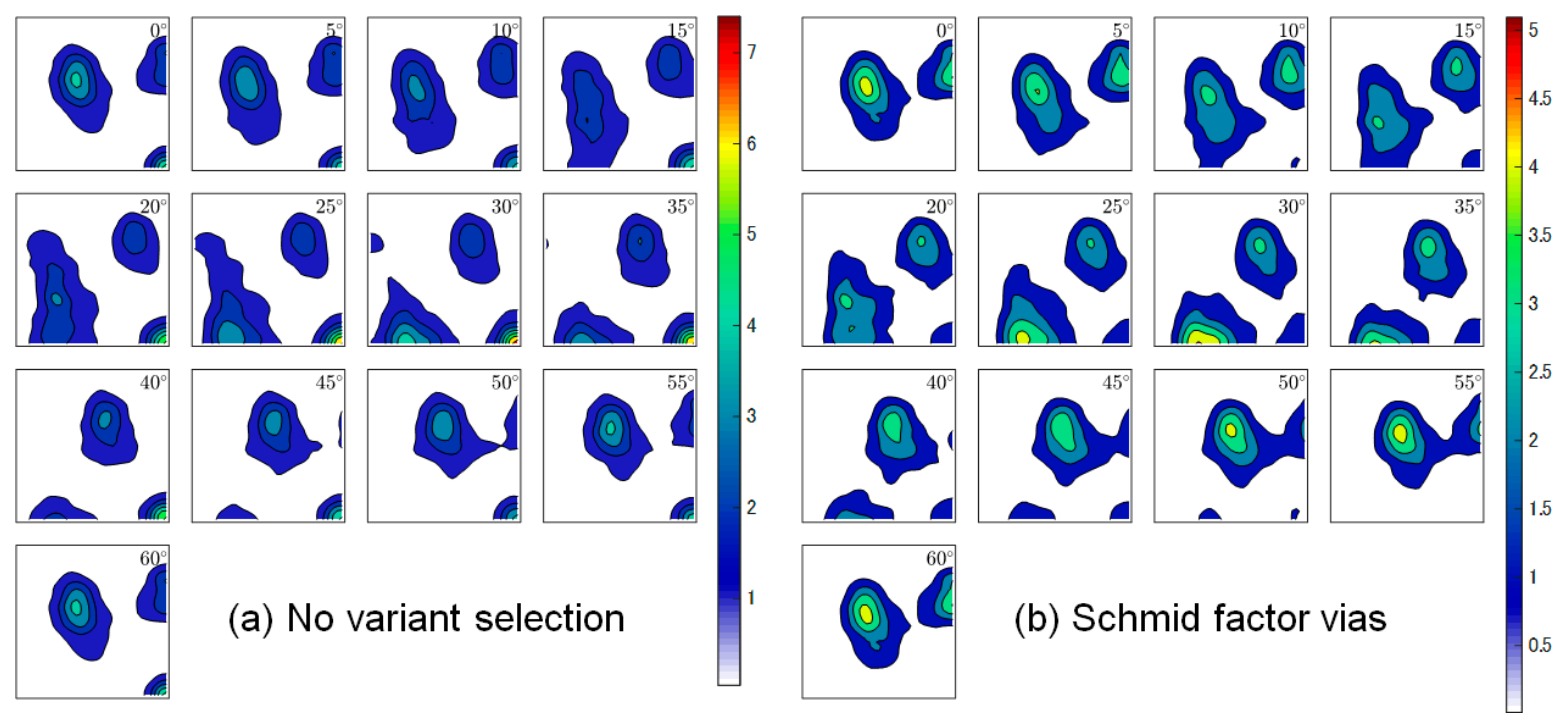

Figure 9. $\varphi_{2}$ sections of the calculated ODF of the $\varepsilon$ martensite from the ODF of the austenite at $E=0.42$ (a) without a variant selection rule and (b) with the Schmid-factor-based variant selection.

\section{2. $\gamma \rightarrow \alpha^{\prime}$ or $\gamma \rightarrow \varepsilon \rightarrow \alpha^{\prime}$ Transformation}

To understand the variant selection involved in the formation of the $\alpha^{\prime}$ martensite phase, the orientations corresponding to the $24 \mathrm{~K}-\mathrm{S}$ variants were calculated by using the Bowles-Mackenzie theory. The angle between $(011)_{\alpha^{\prime}}$ and $(111)_{\gamma}$ was $0.56^{\circ}$, and that between $[\overline{101}]_{\gamma}$ and $[\overline{111}]_{\alpha^{\prime}}$ was $3.72^{\circ}$ for the calculated orientation relationship. Hence, this was close to the Nishiyama-Wasserman $(\mathrm{N}-\mathrm{W})$ relationship, $(111)_{\gamma} \|(011)_{\alpha^{\prime}}$, $[11 \overline{2}]_{\gamma} \|[01 \overline{1}]_{\alpha^{\prime}}$, rather than K-S relationship. However, it was difficult to distinguish the $\mathrm{K}-\mathrm{S}$ and $\mathrm{N}-\mathrm{W}$ relationships in the plastically deformed microstructure, which could be attributed to the large in-grain orientation distribution.

Figure 7 shows the EBSD analysis results, which capture the important features for the consideration of the transformation mechanism; the Q2 and 30RC-oriented $\alpha^{\prime}$ martensite regions existed adjacent to each other. The pole figures revealed that these orientations closely shared one $\{111\}$ pole direction and three $\{110\}$ pole directions (Figure $7 \mathrm{f}$ ). The combination of variants reproducing this situation is shown in Figure 10 by setting the initial matrix orientation as the RB.


Figure 10. Two variants, V1 (red) and V2 (blue), of the $\alpha$ 'martensite transformed from an RB-oriented $\gamma$ matrix (green) shown in (a) $\{111\},(\mathbf{b})\{110\}$, and (c) $\{001\}$ pole figures.

According to the grouping of variants by Takayama et al. [18], the relative relationship between these variants was V1/V2, which has also been observed in thermal martensite. 
Although these variants shared the close-packed (011) plane, they belonged to different Bain groups. In addition, the shared (011) plane was perpendicular to the tensile axis (Figure 10b). By considering the sequential $\gamma \rightarrow \varepsilon \rightarrow \alpha^{\prime}$ transformation, that is, $(111)_{\gamma}\left\|(0001)_{\varepsilon}\right\|(011)_{\alpha^{\prime}}$ the preceding orientation of the $\varepsilon$ phase should be S2. However, because the Schmid factor for S2 formation was zero, it is considered that the $\alpha^{\prime}$ martensite phases were formed via the $\gamma \rightarrow \alpha^{\prime}$ route.

In addition, the $\alpha^{\prime}$ martensite orientations were relatively different from the 30RC and Q2 orientations (Figure 10). By rotating the pole figures $15-20^{\circ}$ clockwise along the $\mathrm{ND}$, their orientations were consistent with the main component of the textures. Consequently, the matrix orientation was brass, $\{011\}<211>$. This indicates that the observed RBs, $\{011\}<111>$, in Figure 7c can be considered as the survived orientation, rather than the matrix orientation.

Nevertheless, the $\gamma \rightarrow \varepsilon \rightarrow \alpha^{\prime}$ route was not necessarily denied. The M-oriented $\varepsilon$ martensite transformed into $\alpha^{\prime}$ martensite with a 30RC component (Table 2, No. 3). This could be the reason for the domination of the texture by the $30 \mathrm{RC}$. In addition, the acceleration in the increase of the volume fraction of the $\alpha^{\prime}$ phase at a true strain of approximately 0.24 (Figure 2) could be attributed to the onset of the $\gamma \rightarrow \alpha^{\prime}$ and $\gamma \rightarrow \varepsilon \rightarrow \alpha^{\prime}$ transformations. As described in Part I, the dislocation structure in the matrix also starts changing at a true strain of 0.24 , indicating a change in the plastic deformation mechanism.

Table 2. Orientations after the $\varepsilon \rightarrow \alpha$ transformation from $\left(\varphi_{1}, \Phi, \varphi_{2}\right) \varepsilon=\left(32.5^{\circ}, 42.5^{\circ}, 5.0^{\circ}\right)$.

\begin{tabular}{|c|c|c|c|c|c|}
\hline No. & $\begin{array}{c}\text { Directional } \\
\text { Correspondenc }\end{array}$ & & $\varphi_{1}$ & $\Phi$ & $\varphi_{2}$ \\
\hline 1 & {$[2 \overline{110}]_{\varepsilon} \|[1 \overline{1} 1$} & 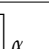 & $72.0^{\circ}$ & $73.7^{\circ}$ & $37.4^{\circ}$ \\
\hline 2 & {$[2 \overline{2110}]_{\varepsilon}^{\varepsilon}, \| \overline{111}$} & $\int_{\alpha}^{\alpha}$ & $107.9^{\circ}$ & $33.9^{\circ}$ & $67.6^{\circ}$ \\
\hline 3 & {$[\overline{1} 2 \overline{1} 0]_{\varepsilon}^{\varepsilon} \|[1 \overline{1} 1$} & $\int_{\alpha}^{\alpha}$ & $208.2^{\circ}$ & $2.5^{\circ}$ & $4.1^{\circ}$ \\
\hline 4 & 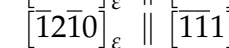 & $\int_{\alpha}^{\alpha}$ & $326.9^{\circ}$ & $46.9^{\circ}$ & 29.5 \\
\hline 5 & {$[\overline{11} 20]_{\varepsilon}^{\varepsilon} \|[1 \overline{1} 1$} & $\int_{\alpha}^{\alpha}$ & $352.7^{\circ}$ & $73.5^{\circ}$ & $52.3^{\circ}$ \\
\hline 6 & {$[\overline{1120}]_{\varepsilon} \|^{\varepsilon}[\overline{111}$} & $\int_{\alpha}^{\alpha}$ & $39.7^{\circ}$ & $87.1^{\circ}$ & $6.9^{\circ}$ \\
\hline
\end{tabular}

* The plane correspondence listed here is $(0001)_{\varepsilon} \|(011)_{\alpha}$.

\section{Conclusions}

Herein, the DIMT of SUS 304 stainless steel was investigated based on the texture development. The overall textures of the $\gamma$ austenite, $\varepsilon$ martensite, and $\alpha^{\prime}$ martensite were determined by using the in situ neutron diffraction technique. Combined with the microtextures measured by EBSD, the mechanisms of the DIMT of the steel sample were discussed based on the neutron diffraction results. The results revealed that the main components of the texture of the $\varepsilon$ martensite corresponded to those of $\gamma$ austenite. The variant selection was qualitatively explained by the Schmid factors on $\{111\}\langle\overline{2} 11\rangle$ slip systems. In addition, the volume fraction of the $\alpha^{\prime}$ martensite phase observed by EBSD was higher than that observed by neutron diffraction. This suggests that $\varepsilon \rightarrow \alpha^{\prime}$ DIMT easily occurred. At a true strain of 0.42 , a packet structure consisting of two variants of $\alpha^{\prime}$ martensite was observed. However, their expected original orientation did not correspond to either the main components in the $\gamma$ or $\varepsilon$ phases. This suggests that the $\gamma \rightarrow \alpha^{\prime}$ type DIMT consumed the lost component in the $\gamma$ matrix, such as the brass component, $\{011\}<211>$. The results of this study indicate that the $\gamma \rightarrow \varepsilon \rightarrow \alpha^{\prime}$ DIMT was first activated, and then the $\gamma \rightarrow \alpha^{\prime}$ DIMT was activated after a certain increment in strain.

Author Contributions: Conceptualization, Y.O. and S.S.; methodology, Y.O. and S.S.; formal analysis, Y.O.; investigation, Y.O.; writing —original draft preparation, Y.O.; writing-review and editing, S.S.; visualization, Y.O.; funding acquisition, Y.O. and S.S. Both authors have read and agreed to the published version of the manuscript.

Funding: This research was funded by the local government of the Ibaraki prefecture. 
Institutional Review Board Statement: Not applicable.

Informed Consent Statement: Not applicable.

Data Availability Statement: The data presented in this study are available on request from the corresponding author. The data are not publicly available since the sharing repository of the author's institute is not yet ready.

Acknowledgments: The authors appreciate the kind support provided by the iMATERIA team, Ibaraki University, and staff at J-PARC MLF. The neutron experiment was conducted as part of the research proposal 2019PM3002. The authors also acknowledge YONEKURA MFG Co., Ltd., for developing the special deformation-testing machine for the in situ neutron diffraction experiment.

Conflicts of Interest: The authors declare no conflict of interest.

\section{References}

1. Nishiyama, Z. Martensitic Transformation; Fine, M.E., Meshii, M., Wayman, C.M., Eds.; Academic Press Inc.: New York, NY, USA, 1978.

2. Nohara, K.; Ono, Y.; Ohashi, N. Composition and Grain Size Dependencies of Strain-induced Martensitic Transformation in Metastable Austenitic Stainless Steels. Tetsu-to-Hagane 1977, 63, 772-782. [CrossRef]

3. Miura, R.; Ohnishi, K.; Nakajima, H.; Shimamoto, S. Effects of Carbon and Nitrogen on the Tensile Deformation Behavior of SUS304 and 316 Stainless Steels at Cryogenic Temperatures. Tetsu-to-Hagane 1987, 73, 715-722. [CrossRef]

4. Masumura, T.; Nakada, N.; Tsuchiyama, T.; Takaki, S.; Koyano, T.; Adachi, K. The difference in thermal and mechanical stabilities of austenite between carbon- and nitrogen-added metastable austenitic stainless steels. Acta Mater. 2015, 84, 330-338. [CrossRef]

5. Tiamiyu, A.; Tari, V.; Szpunar, J.; Odeshi, A.; Khan, A. Effects of grain refinement on the quasi-static compressive behavior of AISI 321 austenitic stainless steel: EBSD, TEM, and XRD studies. Int. J. Plast. 2018, 107, 79-99. [CrossRef]

6. Onuki, Y.; Sato, S. In Situ Observation for Deformation-Induced Martensite Transformation (DIMT) during Tensile Deformation of 304 Stainless Steel Using Neutron Diffraction. PART I: Mechanical Response. Quantum Beam Sci. 2020, 4, 31. [CrossRef]

7. Wenk, H.; Lutterotti, L.; Vogel, S. Rietveld texture analysis from TOF neutron diffraction data. Powder Diffr. 2010, 25, 293-296. [CrossRef]

8. Bachmann, F; Hielscher, R.; Schaeben, H. Texture Analysis with MTEX-Free and Open Source Software Toolbox. Solid State Phenom. 2010, 160, 63-68. [CrossRef]

9. Bunge, H.-J. Texture Analysis in Materials Science; Butterworth-Heinemann: Oxford, UK, 1982.

10. Bowles, J.S.; Mackenzie, J.K. The crystallography of martensite transformations III. Face-centred cubic to body-centred tetragonal transformations. Acta Metall. 1954, 2, 224-234. [CrossRef]

11. Onuki, Y.; Hoshikawa, A.; Sato, S.; Ishigaki, T. Rapid Measurement of Texture of Metals by Time-of-Flight Neutron Diffraction at iMATERIA and its Applications. Mater. Sci. Forum 2016, 879, 1426-1430. [CrossRef]

12. Tomida, T.; Wakita, M.; Yasuyama, M.; Sugaya, S.; Tomota, Y.; Vogel, S.C. Memory effects of transformation textures in steel and its prediction by the double Kurdjumov-Sachs relation. Acta Mater. 2013, 61, 2828-2839. [CrossRef]

13. Onuki, Y.; Masumura, T.; Tsuchiyama, T.; Sato, S.; Tomida, T.; Takaki, S. Mutual Verification of Phase Fraction Analysis Techniques for Steels Comprising Deformation Induced Martensite Phases: Neutron-Diffraction-Based Rietveld Texture Analysis and Saturation Magnetization Measurement. Tetsu-to-Hagane 2020, 106, 457-464. [CrossRef]

14. Burgers, W. On the process of transition of the cubic-body-centered modification into the hexagonal-close-packed modification of zirconium. Physica 1934, 1, 561-586. [CrossRef]

15. Yamashita, T.; Koga, N.; Umezawa, O. Influence of Deformability of Retained Austenite on Martensitic Transformation in Tension for Low Alloy Steel at Low Temperatures. ISIJ Int. 2018, 58, 1155-1161. [CrossRef]

16. Kwon, E.; Fujieda, S.; Shinoda, K.; Suzuki, S. Texture evolution and fcc/hcp transformation in Fe-Mn-Si-Cr alloys by tensile deformation. Mater. Sci. Eng. A 2010, 527, 6524-6532. [CrossRef]

17. Matsumura, O.; Furusako, S.; Furukawa, T.; Otsuka, H. Formation of Surface Texture and Anisotropy of Shape Memory Effect in an Fe-Mn-Si Alloy. ISIJ Int. 1996, 36, 1103-1108. [CrossRef]

18. Takayama, N.; Miyamoto, G.; Furuhara, T. Effects of transformation temperature on variant pairing of bainitic ferrite in low carbon steel. Acta Mater. 2012, 60, 2387-2396. [CrossRef] 